\title{
Thirty deaths from asthma
}

\author{
F CARSWELL
}

Royal Hospital for Sick Children, Bristol

SUMmaRY The features associated with 30 childhood deaths from asthma in the period 1962-83 are reviewed. There was an annual death rate of $0 \cdot 47 / 100000$ population at risk in the later part of this period in Avon county. Asthma deaths occurred in chronic severe sufferers at night and, although there was usually time for effective treatment, inadequate management probably contributed to the deaths, with deficiencies in corticosteroid treatment being a major feature. Twelve of the 30 patients who died had never attended hospital. A greater proportion of girls died than would have been predicted from the proportion attending hospital. The survey indicates a need for more effective education of laymen and doctors on asthma.

Children still die of asthma in England but the circumstances producing these deaths have not been reviewed recently. The recent survey of deaths in English adults ${ }^{1}$ and the last (1969) English survey which included deaths in childhood ${ }^{2}$ both suggested that most deaths were potentially avoidable.

Surveys in London and Newcastle ${ }^{34}$ suggest that childhood asthma is being underdiagnosed and undertreated. Despite many leading articles and reviews $^{5-9}$ and the increased admission rates of asthmatic children to hospital, there is little evidence of a decline in paediatric mortality. The present survey was carried out to ascertain the circumstances of the deaths and to decide if these were avoidable.

\section{Methods}

The number of deaths from asthma during 1962-82 inclusive were sought by reviewing the discharges from the Avon county hospitals which treat children (Bristol Royal Hospital for Sick Children, Southmead, Ham Green, and Frenchay Hospitals); by examining the paediatric pathologist's records; and by obtaining copies of death certificates from the Office of Population Censuses and Surveys (OPCS).

Table 1 indicates the number found from each of the three sources and compares this with the maximum that could have been found from that source. The two deaths not found from the OPCS data had had the diagnosis of asthma confirmed at necropsy. Only two of the four deaths traced by review of hospital inpatient deaths could have been found from the pathologist's records. All the Avon county hospital records for the 28 children so discovered were examined. A further two patients
Table 1 Number of deaths traced compared with maximum that could have been found from each source (Avon county only)

\begin{tabular}{lcl}
\hline Source of death record & No & Potential no \\
\hline Hospital discharge and deaths & 4 & 11 \\
Pathologist's records & 9 & 18 \\
Office of Population Censuses and Surveys & 26 & 28
\end{tabular}

whose deaths were known to the author because of the request for a medico-legal opinion are included, although they died outside Avon. No general attempt was made to obtain family practitioner records or to contact clinicians or relatives but this information was available for the two patients dying outside Avon county. To assess the severity of the asthma before the fatal attack, control data were obtained from 10 asthmatic patients attending Bristol Children's Hospital. These controls (mean age 7.7 years; seven girls, three boys) were selected from 40 patients attending Bristol Children's Hospital because only they were similar to the dying patients in that the asthma had been present for at least a year and they had started wheezing before 3 years of age.

Data on all inpatient discharges and outpatient attendances over measured periods were reviewed to ascertain if the age and sex ratio of those patients treated at hospital reflected appropriately the pattern of those dying.

\section{Results}

The deaths of 30 children (18 boys; 12 girls) whose mean age at death was 8.5 years (range 1.3 to 14.9 years) were reviewed. Numbers were consecutively 
allocated; cases 1 to 18 died in the period 1962-9; cases 19 to 29 in 1970-82; and case 30 in 1983. The documentation was often deficient, especially with regard to the final treatment of the 19 who suffered respiratory arrest before arriving at hospital. One patient (case 8) died five minutes after entering the accident and emergency department. Cases 28 and 30 died outside Avon, but were particularly well documented. All 19 necropsies indicated severe asthma. ${ }^{10}$ One patient (case 22) also had a pneumothorax.

Pattern before last attack. Table 2 documents the severity of the asthma before the final attack. Twelve patients were known to have been receiving prophylactics (including bronchodilators, cromoglycate, and, in two, theophylline) reasonably regularly before death. Only two patients underwent respiratory function measurements before the fatal attacks. The patient in case 26 was attending the asthma clinic. Her forced expiratory volume was 30 to $50 \%$ of the predicted normal value on the five occasions on which it was measured in the last year of her life. The value recorded six days before death was unremarkable. The patient in case 19 had a forced expiratory volume:forced vital capacity ratio of $68 \%$ recorded some months before death.

Month and time of death. Ten deaths occurred between May and July; eight between August and October; seven between November and January; and five between February and April. There was no difference in the distribution between the sexes.

In 11 of the 14 children in whom the time of the terminal respiratory arrest had been recorded, it occurred between $6.00 \mathrm{pm}$ and $6.00 \mathrm{am}$. Five deaths were between midnight and $4.00 \mathrm{am}$. There were no

Table 2 Severity of asthma before the fatal attack and hospital attendance in 30 children who died and 10 controls

\begin{tabular}{lll}
\hline & Patients & Controls \\
\hline $\begin{array}{l}\text { Duration of asthma; mean (range) in years } \\
\text { Number (\%) with onset at less than }\end{array}$ & $5 \cdot 8(0 \cdot 5-13 \cdot 1)$ & - \\
3 years of age & $13(93)$ & $10(100)$ \\
$\begin{array}{l}\text { Number (\%) with onset more than one } \\
\text { year before death }\end{array}$ & $16(94)$ & $10(100)$ \\
$\begin{array}{l}\text { Number (\%) with previously recorded } \\
\text { cyanotic attacks }\end{array}$ & $8(67)$ & $1(10)$ \\
$\begin{array}{l}\text { Number (\%) with probable reduced growth* } \\
\text { Number attending hospital for asthma }\end{array}$ & $5(56)$ & $2(20)$ \\
$\quad \begin{array}{l}\text { Never } \\
\text { Other than in year before death } \\
\text { In year of death }\end{array}$ & 12 & - \\
$\quad$ As outpatients only & 5 & - \\
As inpatients $+/-$ outpatients & 5 & - \\
\hline
\end{tabular}

${ }^{*}$ Reduced growth was defined as having a weight less than the 25 th centile for age without a similarly reduced height. differences in the pattern between the sexes or when the nine deaths occurring outside hospital were compared with the five inside. Although at least four patients were mechanically ventilated after the initial (and eventually fatal) respiratory arrest, none were ventilated before this.

Duration of the fatal attacks. In 13 children the duration of the last attack could be reliably estimated. One died within an hour of the start of the attack; three died less than 12 hours after the start; and seven died after more than 12 hours. The two patients who were found unexpectedly in respiratory arrest were known, severe asthmatics. There was usually time for treatment to be effective.

Treatment in the last attack. The treatment received varied considerably and no details are available for many treated outside hospital. In some patients emergency treatment seemed optimum. Thus the patient in case 30 had returned to the house in the evening and was observed to be wheezing by his parents for only five minutes before they called the general practitioner, who arrived five minutes later and instituted treatment. He received intravenous bronchodilator and corticosteroid as well as oxygen 30 minutes before death. Hospital notes indicated that the parents had previously had difficulty in supervising and managing his asthma effectively. This death may be partly explained as a failure to educate the child's family on the severity of his asthma, as this child had previously been admitted, cyanosed and unconscious, to hospital.

There was often parental lack of understanding of the severity of the child's asthma, for example cases 8 and 10 . One, case 29, stopped his prophylactic medicine (? theophylline) two days before death. Such mismanagement was commonly compounded by the failure of the attending physician to appreciate the severity of the acute attack and by inappropriate or ineffectual treatment (Table 3). Sedative compounds, including antihistamines, were

Table 3 Adequacy of treatment in the final attack in 30 children who died of asthma

\begin{tabular}{ll}
\hline & No \\
\hline $\begin{array}{l}\text { Died at home or in ambulance } \\
\text { Died in hospital }\end{array}$ & 19 \\
$\begin{array}{l}\text { Patients for whom details of treatment available } \\
\text { Received adequate corticosteroids ( }>1 \mathrm{mg}\end{array}$ & 13 \\
$\quad$ prednisolone/kg/day) & 2 \\
Received a sedative during final attack & 5 \\
Judged inadequately treated* & 9 \\
\hline
\end{tabular}

${ }^{*}$ Two of these children probably did not take prescribed treatment; there were often multiple inadequacies. 
used throughout the period of survey. One patient (case 28), who was not given oxygen, had a hypoxic arrest five hours after admission to hospital.

Corticosteroid treatment. Often this was either not given (cases $6,8,11,17,22,23$, and 26) or given in inadequate dosage (defined as less than $1 \mathrm{mg} / \mathrm{kg} /$ day prednisolone-cases $1,7,9$, and 28) in the acute attack. The patient in case 9 was treated with $0.5 \mathrm{mg}$ prednisolone $/ \mathrm{kg} /$ day in the fatal attack but had previously responded in a similar attack when given $1.3 \mathrm{mg}$ prednisolone $/ \mathrm{kg} /$ day. In two patients (cases 19 and 30) systemic corticosteroids were given in effective dosage. None of the three (cases 11, 17, and 26) who were found dead received corticosteroids in their final attack.

In a number of patients, previous treatment should have indicated their particular need for steroids. Case 26 had received intramuscular tetracosactrin, $0.15 \mathrm{mg}$ twice weekly for four months in 1973. This had been gradually reduced over a 12 month period while beclomethasone, taken by pressurised inhaler, was increased to $500 \mu \mathrm{g} /$ day. She continued on the same dose of beclomethasone for the 19 months before her death. An intramuscular tetracosactrin test carried out four months before death showed a fasting cortisol concentration of 220 $\mathrm{nmol} / \mathrm{l}(7.9 \mu \mathrm{g} / 100 \mathrm{ml})$ rising to $1035 \mathrm{nmol} / \mathrm{l}(37.5$ $\mu \mathrm{g} / 100 \mathrm{ml}$ ) in one hour-a normal response in our laboratory. This patient was overweight and knew her obesity and pubertal acne were induced in part by her steroid treatment. It is probable that she was attempting to reduce the dose when she died. Four others (cases 19, 22, 24, and 25) had taken steroids within the previous two weeks but were likely to have stopped or reduced the dose around the time of the final attack. Case 1 had spent three years at a boarding school for delicate children in an attempt to control his asthma and had also been receiving corticosteroids for three years before his death. Although he was regularly receiving $10 \mathrm{mg} /$ day before admission, he was given only $10 \mathrm{mg}$ prednisolone in hospital in the 12 hours between admission in severe status asthmaticus and death. Adrenal hypoplasia was not found at necropsy in any subject.

Pattern of hospital asthma patients. Ninety seven girls and 167 boys with asthma were discharged from Bristol Children's Hospital in 1981. Their mean age was 6.4 years; 68 boys and 33 girls were aged less than 5 years. All asthmatic patients (inpatients and outpatients) seen personally for the first time between July 1982 and June 1983 inclusive were also reviewed. Their mean age was 6.6 years. A minority of the boys and girls referred were less than 5 years of age (17 of 40 and 5 of 14 respectively).

\section{Discussion}

More asthma deaths were found by using multiple sources than would have been produced from OPCS figures alone. Deaths in cases 23 and 27 were only found from hospital and pathologist's records. False positive and false negative certifications of asthma have been described ${ }^{11}$ but Fraser $e t a^{2}$ found only one case out of 45 necropsies in which the clinical diagnosis of asthma was not confirmed. Similarly, the 19 necropsies in this series confirmed the diagnosis and did not lead unexpectedly to a changed diagnosis in any case.

This survey includes 18 deaths (11 boys; 7 girls) in the 1960s when there was a considerable increase in asthma deaths $s^{6-7}$ which has been related to excessive use of isoprenaline. The conventional view, however ${ }^{7}$ is that if there was a causal link between the increased usage of the bronchodilator aerosols and the increase in asthma deaths this was because too great a reliance was placed on their efficacy, so that beginning the necessary additional treatment was delayed to a point at which the patient was beyond help. This seems possible in the present series as only seven of these 18 deaths occurred in hospital. Details are not available for most of them. Two children (cases 9 and 13) were known to take 'excessive' doses of isoprenaline, as did case 30 of salbutamol. These excessive doses are common in surviving patients.

The estimated population in Avon county is 163400 children less than 15 years of age (OPCS, 1981 census). The annual death rate for childhood asthma in Avon county from this survey is $0.47 /$ 100000 if one considers only the deaths in 1970-82. If one assumes a $10 \%$ prevalence of asthma in childhood, this leads to the statement that approximately 1 in 21000 asthmatics die of asthma each year.

The apparent increase of deaths in May, June, and July might have been related to grass pollen sensitivity. Detailed comparison, however, of the date and the time of the deaths with the pollen count do not suggest this as a major cause.

In this series deaths occurred principally in the evening or night. This has previously been reported in some adult studies ${ }^{12}$ but not for children. The nocturnal prevalence may be related to the phenomenon of 'morning dipping' ${ }^{13}$ in which the peak expiratory flow rate falls to its lowest value in the morning. This has been described in both normal and asthmatic subjects, in whom it is particularly noticeable. Dipping may also occur in the evening. It may be explained by the low concentrations of adrenal medullary and adreno-cortical hormones found in the blood at these times, or it could be 
related to the increased irritability of the airways at such times of the day.

A major feature of this series is the inadequacy of the acute treatment in the fatal attack (Table 3). This judgement is retrospective by a single physician and is, therefore, likely to be biased, but the pattern agrees with worldwide experience. ${ }^{14} 15$ The failure to give adequate corticosteroid treatment was probably a major contributory factor in the deaths in the series. Adrenal insufficiency consequent upon maintenance steroid treatment could also have played a part ${ }^{14}$ but there was no direct evidence of this. There is a need for corticosteroid treatment in acute asthmatic attacks in children recently on either oral ${ }^{14}$ or inhaled ${ }^{16}$ steroids. The inadequate corticosteroid dosage found in the acute attack in this study has been observed previously in studies on adults ${ }^{1}$ and children. ${ }^{214}$ There was no evidence of any increase in steroids or reduction in sedative prescriptions similar to that found in the London inpatient survey ${ }^{9}$ over the 20 years of review.

This series does not contain any deaths that were very sudden and unexpected as was a feature of some other reports, notably from Australia,${ }^{14}$ where adrenal insufficiency was present and may have altered the pattern. It is commonly difficult to obtain proof that death was unpredictably sudden. ${ }^{17}$ Case 10 died when he was frightened during an asthma attack from which he was apparently recovering. The two patients found in respiratory arrest were chronically, severely affected, and death, at least in retrospect, was not unpredictable. Case 30 died within 50 minutes of the apparent onset of his attack. This patient's death seems to have occurred despite very effective treatment which could suggest that he was an 'unavoidable' death, but there are indicators of suboptimal management before the attack. There was time in most cases for treatment to have been effective if given early in the attacks. Only a minority of patients were on regular prophylaxis which, if taken, could have reduced the severity of the last attack.

The patients who died had even more severe asthma than the controls, who were selected for factors which predict severe asthma ${ }^{18}$ from a four times larger group of hospital referrals.

The review of patients seen at hospital suggests that the patients are not referred in the proportions one would have predicted from the deaths. Thus, although the mortality in boys and girls under 5 years is identical (OPCS figures), more than twice as many boys were seen at hospital. Twelve of the children who died had never attended hospital in life. This probably reflects a failure to appreciate the severity of their asthma.

The 30 deaths reviewed were a result of the interaction of severe asthma, inadequately assessed by the parents and medical staff, patient noncompliance, and faulty medical treatment. With modern treatment delivered early, many of these children would have survived. The survey supports the view that undertreatment is the major problem. ${ }^{3}{ }^{4}$ Efforts should be made to reach and treat those asthmatics ${ }^{3}$ who would not otherwise receive appropriate information and treatment. The school system provides a potentially simple access to these children and use of this should be fully investigated. Furthermore, a major educational effort is required to improve understanding and management of asthma among both the public and the medical profession.

I gratefully acknowledge the cooperation of the Office of Population Censuses and Surveys, Dr Norman Brown, and Dr Pat McKeever.

\section{References}

1 British Thoracic Association. Death from asthma in two regions of England. Br Med J 1982;285:1251-5.

${ }^{2}$ Fraser PM, Speizer FE, Waters SDM, Doll R, Mann NM. The circumstances preceding death from asthma in young people in 1968 to 1969 . Br J Dis Chest 1971;65:71-84.

${ }^{3}$ Anderson HR, Bailey PJ, West S. Community survey of the drug treatment of asthma and wheezing in children. Thorax 1981;36:222-3

${ }^{4}$ Speight ANP, Lee DA, Hey EN. Under diagnosis and under treatment of asthma in childhood. Br Med J 1983;286:1253-6.

5 Anonymous. Increasing deaths from asthma [Editorial]. Br Med J 1968;i:329-30.

${ }^{6}$ Standing Medical Advisory Committee. Deaths from asthma. Edinburgh: HMSO Press, 1973.

7 Office of Health Economics. Asthma, current health problems. No 57. Luton: White Crescent Press Ltd, 1976.

${ }^{8}$ Anonymous. Acute severe asthma [Editorial]. Lancet 1982;ii:420-1.

9 Anderson HR, Bailey P, West S. Trends in the hospital care of acute asthma 1970-8; a regional study. $B r$ Med J 1980;iv: 1191-94.

${ }^{10}$ Dunnill MS. Asthma. In: Dunnill MS, ed. Pulmonary pathology. London: Churchill, 1982:50-66.

" Ormerod LP, Stableforth DE. Asthma mortality in Birmingham 1975-7: 53 deaths. Br Med J 1980;280:687-90.

12 Hetzel MR, Clarke TJH, Branthwaite MA. Asthma; analysis of sudden deaths and ventilatory arrests in hospital. $\mathrm{Br}$ Med $\mathrm{J}$ 1977;i:808-11.

13 Turner-Warwick M. On observing patterns of air flow obstruction in chronic asthma. Br J Dis Chest 1977;71:73-86.

14 Mellis CM, Phelan PD. Asthma deaths in children - a continuing problem. Thorax 1977;32:29-34.

15 Collins-Williams C, Zalesky C, Battu K, Chambers MT. Death from asthma. Can Med Assoc J 1981;125:341-5.

16 Anonymous. Deaths from asthma in children on aerosol corticosteroids [Editorial]. Br Med J 1977;ii:1117.

17 Cushley MJ, Tattersfield AE. Sudden death in asthma; discussion paper. J Roy Soc Med 1983;76:662-5.

${ }^{18}$ Martin AJ, McLennan LA, Landau LI, Phelan PD. The natural history of childhood asthma to adult life. Br Med J 1980;ii: 1397-400.

No reprints available; correspondence to Dr F Carswell, Royal Hospital for Sick Children, Bristol BS2 8BJ.

Received 5 October 1984 